\title{
Let's get fISSical: fast in silico synchronization as a new tool for cell division cycle analysis
}

\author{
BROOKE MORRISWOOD* and MARKUS ENGSTLER \\ Department of Cell छ Developmental Biology, University of Würzburg, Biocentre, Am Hubland, 97074 Würzburg, \\ Germany
}

(Received 29 September 2016; revised 23 December 2016; accepted 5 Fanuary 2017; first published online 7 February 2017)

SUMMARY

Cell cycle progression is a question of fundamental biological interest. The coordinated duplication and segregation of all cellular structures and organelles is however an extremely complex process, and one which remains only partially understood even in the most intensively researched model organisms. Trypanosomes are in an unusual position in this respect they are both outstanding model systems for fundamental questions in eukaryotic cell biology, and pathogens that are the causative agents of three of the neglected tropical diseases. As a failure to successfully complete cell division will be deleterious or lethal, analysis of the cell division cycle is of relevance both to basic biology and drug design efforts. Cell division cycle analysis is however experimentally challenging, as the analysis of phenotypes associated with it remains hypothesisdriven and therefore biased. Current methods of analysis are extremely labour-intensive, and cell synchronization remains difficult and unreliable. Consequently, there exists a need - both in basic and applied trypanosome biology - for a global, unbiased, standardized and high-throughput analysis of cell division cycle progression. In this review, the requirements both practical and computational - for such a system are considered and compared with existing techniques for cell cycle analysis.

Key words: cell division cycle, synchronization, automation, Trypanosoma brucei, organelles.

\section{INTRODUCTION}

The cell division cycle is an area of fundamental biological interest, and the means by which individual cells duplicate and segregate their organelles underpins processes in both homoeostasis and disease. Trypanosomatids are outstanding model systems for the analysis of eukaryotic cell division cycle progression, due to their highly-polarized cellular structure, possession of several organelles in single-copy number only and the widespread availability of sophisticated molecular cell biology tools and reagents. They are in addition responsible for several neglected tropical diseases. Knowledge of the cell division cycle is thus important not only for understanding of their basic biology, but also for screening and characterizing both candidate and existing drugs. In this review, the current methods for cell division cycle analysis in the African trypanosome, Trypanosoma brucei, will be summarized and a new tool proposed for streamlining this process. The focus is on the replication of cellular organelles and structures rather than the signalling cascades regulating these processes, and the intention is to provide a wide-ranging piece that stimulates discussion and even debate within the broader research community.

\footnotetext{
* Corresponding author: Department of Cell \& Developmental Biology, University of Würzburg, Biocentre, Am Hubland, 97074 Würzburg, Germany. E-mail: brooke.morriswood@uni-wuerzburg.de
}

THE DISEASE IMPACT OF TRYPANOSOMA BRUCEI

Trypanosomatids are responsible for three of the 18 designated neglected tropical diseases (NTDs) (Hotez et al. 2014; World Health Organisation, 2016). Human African trypanosomiasis (HAT), Chagas disease and leishmaniasis respectively afflict members of the poorest human communities in sub-Saharan Africa, Central and South America, and the tropics. In addition, animal African trypanosomiasis depresses economic development and thereby acts to maintain a cycle of poverty (Shaw et al. 2014). HAT, colloquially known as sleeping sickness, is caused by two subspecies of T. bruceiTrypanosoma brucei rhodesiense (in East Africa) and Trypanosoma brucei gambiense (in West and Central Africa) (Franco et al. 2014). The latter is responsible for about $98 \%$ of all clinical cases and is currently the focus of an ongoing and highly successful World Health Organisation campaign; it is estimated that it can be eliminated as a public health concern by 2020 if current rates of decline continue (Simarro et al. 2015). While T. brucei gambiense HAT has traditionally been considered an anthroponotic disease, the existence of both animal reservoirs and asymptomatic human carriers is beginning to be debated (Sudarshi et al. 2014; Berthier et al. 2016; Welburn et al. 2016). Trypanosoma brucei rhodesiense HAT is a zoonosis and the parasite maintains a large reservoir in animals; it cannot therefore be eliminated, though the number of HAT cases it causes

Parasitology (2018), 145, 196-209. C Cambridge University Press 2017. This is an Open Access article, distributed under the terms of the Creative Commons Attribution licence (http://creativecommons.org/licenses/by/4.0/), which permits unrestricted re-use, distribution, and reproduction in any medium, provided the original work is properly cited. 
is much lower (Echodu et al. 2015). Trypanosoma brucei possesses an extremely sophisticated system of antigenic variation, which has consistently thwarted attempts to develop a vaccine; consequently, medical interventions have primarily relied on the use of pharmacological agents. The small number of available drugs and the complicated treatment regimens of existing ones make the need for new drugs an ongoing priority despite the encouraging news from affected areas (Drugs for Neglected Diseases Initiative, 2016).

THE LIFE CYCLE AND MORPHOLOGY OF T. BRUCEI

Trypanosoma brucei is transmitted by its definitive host, the tsetse fly. Tsetse flies, which are haematophagous, become infected when feeding on trypanosomeinfected mammals. Trypanosomes ingested in the blood meal will differentiate in the midgut lumen of the fly into the procyclic trypomastigote form (Vickerman, 1985; Sharma et al. 2009; Rotureau and Van Den Abbeele, 2013). The procyclic cells begin a migration through the tsetse fly, differentiating into mesocyclic forms along the way, until they ultimately reach the salivary glands. There, they differentiate into epimastigote forms and adhere to the salivary epithelium. Mammalian-infectious metacyclic forms are produced in the salivary glands and transmitted to potential mammalian hosts when the fly feeds. Once inside the mammalian tissues, the metacyclics differentiate into the slender bloodstream form (which, like the procyclic, has trypomastigote morphology) and begin to replicate. At high cell densities, a quorum-sensing mechanism stimulates slender bloodstream form cells to differentiate into the non-replicative stumpy form, which is optimized for transmission to the tsetse fly in order to complete the life cycle (Mony et al. 2014). Although T. brucei is primarily considered to inhabit the bloodstream, it is becoming apparent that populations in other tissues may play important roles in maintaining an infection and facilitating subsequent transmission. Its ability to cross the blood-brain barrier is well known, although the timing of this event may be sooner than previously thought (Frevert et al. 2012). Adipose tissue forms have also recently been described, which are metabolically distinct from bloodstream forms, colonize fat tissue, and may serve as reservoirs of infection (Trindade and Rijo-Ferreira et al. 2016). The presence of additional reservoirs in the skin has also been recently demonstrated (Caljon et al. 2016; Capewell and Cren-Travaillé et al. 2016). The existence of other morphological forms in tissues such as the skin is possible.

As noted above, procyclic, bloodstream and adipose tissue forms of $T$. brucei all share a trypomastigote morphology (Hoare and Wallace, 1966; Wheeler et al. 2013a). The cells are rod-shaped with tapered ends, with a single flagellum attached along the long axis and projecting slightly beyond the anterior tip of the cell (Fig. 1A-C). The cell shape, with its sharply-tapered posterior end and more gently tapering anterior part, is maintained by a dense corset of microtubules that lie underneath the plasma membrane (Gull, 1999). The root of the flagellum is within a small invagination of the plasma membrane found near the posterior end of the cell and termed the flagellar pocket (Lacomble et al. 2009) (Fig. 1A). Abutting the flagellar pocket membrane and nucleating the flagellar axoneme is a canonical eukaryote basal body, with an immature probasal body appended orthogonally to it (Lacomble et al. 2010). The flagellum contains an additional accessory structure, the paraflagellar rod, which runs parallel with and is tightly connected to the axoneme (Kohl et al. 1999) (Fig. 1C). Unlike the axoneme, the paraflagellar rod is not found within the portion of the flagellum within the flagellar pocket, and its posterior end is positioned at the point where the flagellum reaches the cell surface. Nucleated between the basal body and probasal body is a specialized quartet of four microtubules, which are thought to have the opposite orientation to the microtubules of the corset (Robinson et al. 1995). This microtubule quartet is wrapped diagonally around the flagellar pocket, and then extends underneath the flagellum to the anterior tip of the cell. Running alongside the microtubule quartet, and physically connected to the paraflagellar rod across the plasma membrane and flagellar membrane, is an electron-dense cytoskeletal filament. The microtubule quartet and the filament together comprise two elements of the flagellum attachment zone, which adheres the flagellum to the cell surface along a helical path (Vaughan et al. 2008; Sunter et al. 2015; Zhou et al. 2015). A recent review has proposed a five-domain descriptive model of the complete flagellum attachment zone (Sunter and Gull, 2016).

The plasma membrane can thus be divided into four morphologically distinct subdomains - the general plasma membrane, the flagellar membrane encasing the axoneme and paraflagellar rod, the flagellar pocket and the flagellar pocket neck (Lacomble et al. 2009). This last subdomain connects the flagellar pocket to the general plasma membrane, and is notable in that its membrane is tightly apposed to that of the flagellum. A number of cytoskeletal complexes are found in the flagellar pocket neck region (Fig. 1A). The best-characterized of these is an electron-dense cytoskeletal barrier element termed the flagellar pocket collar that is positioned at the boundary between the flagellar pocket membrane and the flagellar pocket neck membrane (Perdomo et al. 2015). Above the flagellar pocket collar are at least two other cytoskeletal complexes - the hook complex, which contains the repeat motif protein TbMORN1, and the 


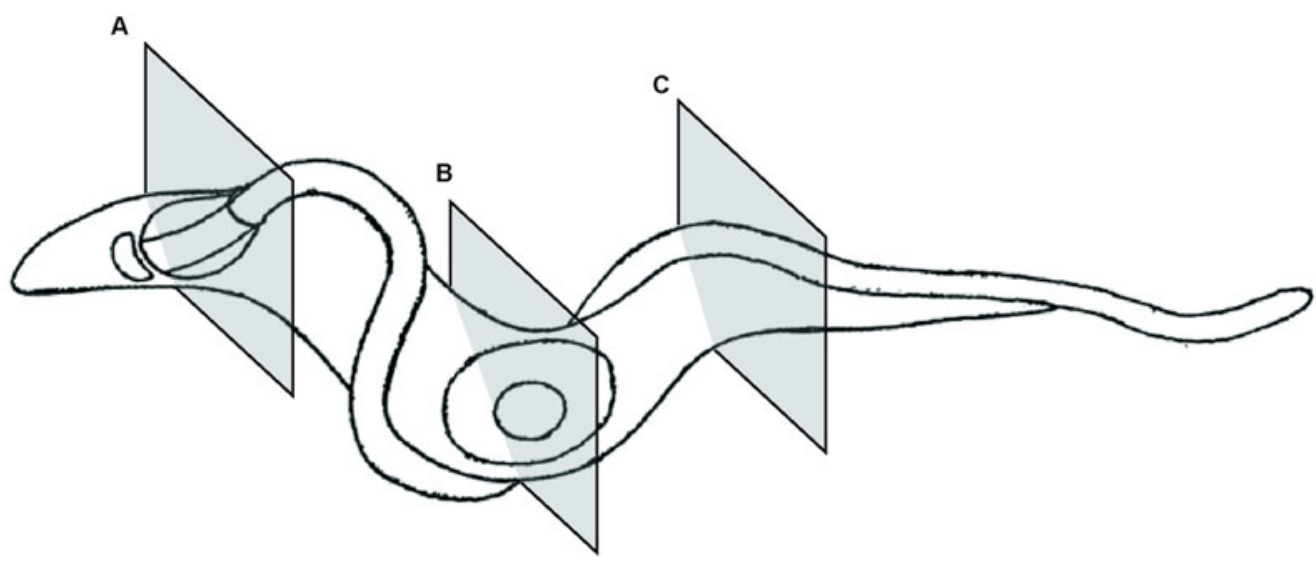

A

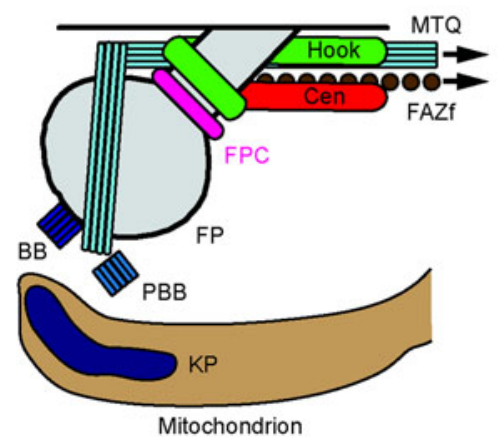

B

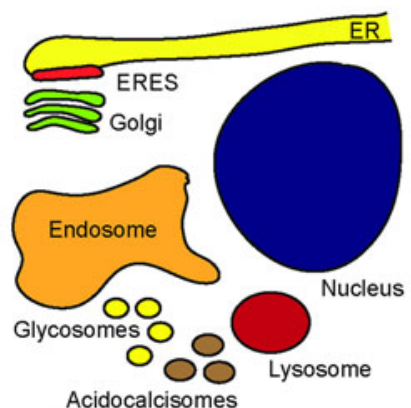

C

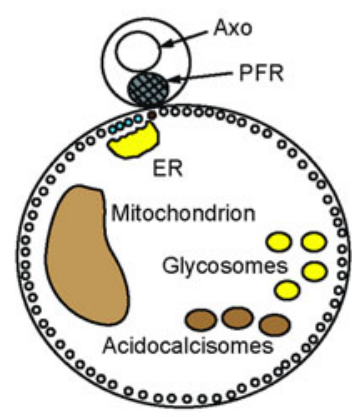

Fig. 1. Cellular structures and organelles of Trypanosoma brucei. A drawing of a trypomastigote cell is shown, with three cross-sections (A-C) indicated. The drawing was made from a single frame of a video of a live, swimming, slender bloodstream form cell. (A) Schematic of structures and organelles in close proximity to the flagellar pocket (FP), shown in oblique cross-section. Indicated structures: basal body (BB), probasal body (PBB), flagellar pocket collar (FPC), hook complex (Hook), centrin arm (Cen), microtubule quartet (MTQ), flagellum attachment zone filament (FAZf). The mitochondrion and its genome, the kinetoplast (KP) are also shown. Note that the MTQ and FAZf extend beyond (arrows) the depicted cross-section, as does the mitochondrion. Not depicted: the tripartite attachment complex that links the BB to the KP. See text for details. (B) Schematic representation of cellular organelles, shown schematically in longitudinal cross-section. ER, endoplasmic reticulum; ERES, endoplasmic reticulum exit site. Note that the ERES and Golgi are in closer proximity to the flagellar pocket than depicted here. (C) Schematic of a transverse cross-section through an anterior part of the cell. The axoneme (Axo) and paraflagellar rod (PFR) within the flagellum are indicated. The ER and mitochondrion extend through the cell and are also shown here. Note that the ER is a network that extends throughout the cell; for simplicity, only the main branch associated with the flagellum attachment zone is depicted here. Note too that panels $(\mathrm{A})-(\mathrm{C})$ are not shown at the same scale.

centrin arm, which contains at least two of the five trypanosome centrin isoforms (Esson et al. 2012).

Within the cytoplasm, the cell contains the generic set of eukaryotic membrane-bound organelles, with some idiosyncrasies. The cell has a single mitochondrion, whose genome (the kinetoplast) is composed of an extremely topologically complex network of interlinked mini- and maxicircles of DNA (Fig. 1A). The kinetoplast is physically linked to the basal body by another transmembrane cytoskeletal complex (Ogbadoyi et al. 2003). The mitochondrion undergoes considerable morphological and metabolic reprogramming during the transition from the bloodstream form to the procyclic form of T. brucei (Vickerman, 1985; Zhang et al. 2010; Gunasekera et al. 2012). The single nucleus, with a diploid complement of DNA, is found anterior of the kinetoplast (Fig. 1B). The endoplasmic reticulum (ER) is dispersed throughout the whole cell volume, with a single ER exit site tightly apposed to the single-stacked Golgi complex on the posterior side of the nucleus and facing the flagellar pocket (He et al. 2004; Ho et al. 2006). All endo- and exocytic activity in $T$. bruce $i$ occurs on the flagellar pocket membrane (Grünfelder et al. 2003; Engstler et al. 2004). Internalized clathrincoated vesicles are routed towards the endosomallysosomal network that is also present between the nucleus and the flagellar pocket (Engstler et al. 2004). Early endosomes are detectable as mostly circular cisternal structures. All cargo delivered to the early endosomes is eventually routed to the recycling endosomes, with a fraction passing first through the late endosomes. The recycling endosomes, which are structurally the most prominent of the endosomal organelles, are the principle recycling factories of 
the cell. The recycling endosomes use clathrincoated vesicles to dispatch material to either the late endosomes or lysosomes; surface glycoproteins are recycled back to the plasma membrane in exocytic carriers. Vesicles with COPI or COPII coats mediate trafficking steps within the endomembrane system (Ho et al. 2006; Sevova and Bangs, 2009; Demmel et al. 2011). Other organelles include glycosomes, which contain the glycolytic enzymes, and acidocalcisomes, which are thought to be involved in osmoregulation (Opperdoes and Borst, 1977; Vercesi et al. 1994).

\section{CELL DIVISION CYCLE OF T.BRUCEI}

The cell division cycle of $T$. brucei has undergone extensive morphological characterization in procyclic and bloodstream form cells, which are the two most experimentally tractable stages of the life cycle (Sherwin and Gull, 1989; Wheeler et al. 2013b) (Fig. 2). The order of events is reckoned to be very similar, although the bloodstream form cells replicate faster $(6 \mathrm{~h}$ in culture as opposed to 9 $\mathrm{h}$ for procyclics, approximately). The earliest documented event in the cell division cycle is the initiation of outgrowth of a new microtubule quartet. This is followed shortly by maturation of the probasal body, which docks with the flagellar pocket membrane and initiates outgrowth of a daughter flagellum (Lacomble et al. 2010). New probasal bodies are formed orthogonal to the old and new mature basal bodies. Replication - defined here as the process of duplication (doubling of mass) followed by segregation (separation into two distinct resolvable structures) - of cellular organelles such as the Golgi, ER exit site and endosomal-lysosomal system follows (Jeffries et al. 2001; Morgan et al., 2001; He et al. 2004; Bangs, 2011). Duplication can be either templated or de novo. Templated duplication entails the old organelle or structure making a physical contribution to the new organelle or structure. De novo duplication utilizes only newly-synthesized material in which the organizational information is intrinsically coded. Replication of the flagellar pocket is coincident with an anticlockwise rotation of the new mature basal body around the pocket to leave it positioned posterior to the old basal body, flagellum and flagellar pocket (Lacomble et al. 2010). During these events, the kinetoplast has been duplicating, and it shortly after segregates into two resolvable structures, temporarily linked by a filamentous structure named the nabelschnur (Gluenz et al. 2011). Nuclear Sphase is completed sometime after that, and the duplicated DNA is segregated into two daughter nuclei in a closed mitosis (Ersfeld and Gull, 1997).

Throughout this time, the new flagellum has been extending towards the anterior end of the cell, using the old flagellum as a guide (Moreira-Leite et al.
2001; Briggs et al. 2004; Hughes et al. 2013). The newly-assembled axoneme and paraflagellar rod within the flagellum are paralleled by construction of the new flagellum attachment zone (Vaughan et al. 2008; Sunter et al. 2015; Zhou et al. 2015). A major difference between procyclic and bloodstream form $T$. brucei is the extent to which the new flagellum elongates along the old one - in procyclics, a 'stop point' is reached around $60 \%$ of the way along the old flagellum, with subsequent growth of the flagellum being driven by backwards extension (Davidge et al. 2006). In bloodstream form cells, the new flagellum continues tracking along the old one almost as far as the anterior tip of the cell body (Hughes et al. 2013). In either position, it is thought that the process of cytokinesis is triggered once the new flagellum attachment zone completes its assembly and contacts an anterior portion of the plasma membrane. Cytokinesis involves formation of a division fold along the anterior-posterior axis, and subsequent ingression of a cleavage furrow along this fold in an anterior-to-posterior direction to leave the two daughter cells joined by a cytoplasmic bridge at their posterior ends (Wheeler et al. $2013 b$ ). Unusually, in trypanosomes the actomyosin system is not involved in cytokinesis (Shi et al. 2000; García-Salcedo et al, 2004). As in other eukaryotes, however, the whole cell cycle process is orchestrated and coordinated by an interplay between several mitotic kinases, of which polo-like kinase (PLK) and aurora kinase are probably the best known (Hammarton, 2007; Li, 2012). The existence and placement of cell cycle checkpoints are not as wellknown as in other model organisms, and it appears likely that trypanosomes have dispensed with some of those present in the opisthokont (animal and fungi) lineages (Hammarton et al. 2003). One of the few known examples of a specific cell cycle checkpoint in $T$. brucei monitors the synthesis of the predominating surface glycoprotein (Sheader et al. 2005). RNAi-mediated depletion of the surface glycoprotein triggers a precise arrest prior to cytokinesis.

Knowledge of the cell division cycle of $T$. brucei is not just of use for understanding of its basic biology. It is also required for determining the mode of action of existing or in-the-pipeline drugs, determining the mechanisms of drug resistance, and for the identification of possible new pathways for pharmacological targeting. However, cell division cycle analysis in $T$. bruce $i$ is currently a very labour-intensive process and could benefit from more standardization and automation. The ability to carry out automated cell division cycle analysis would be of obvious benefits not only to pure but also to applied research, allowing more refined analysis of small molecule screens and forward RNAi screens, amongst other applications. An additional complication for these screens and analyses is the fact that $T$. brucei populations grow 


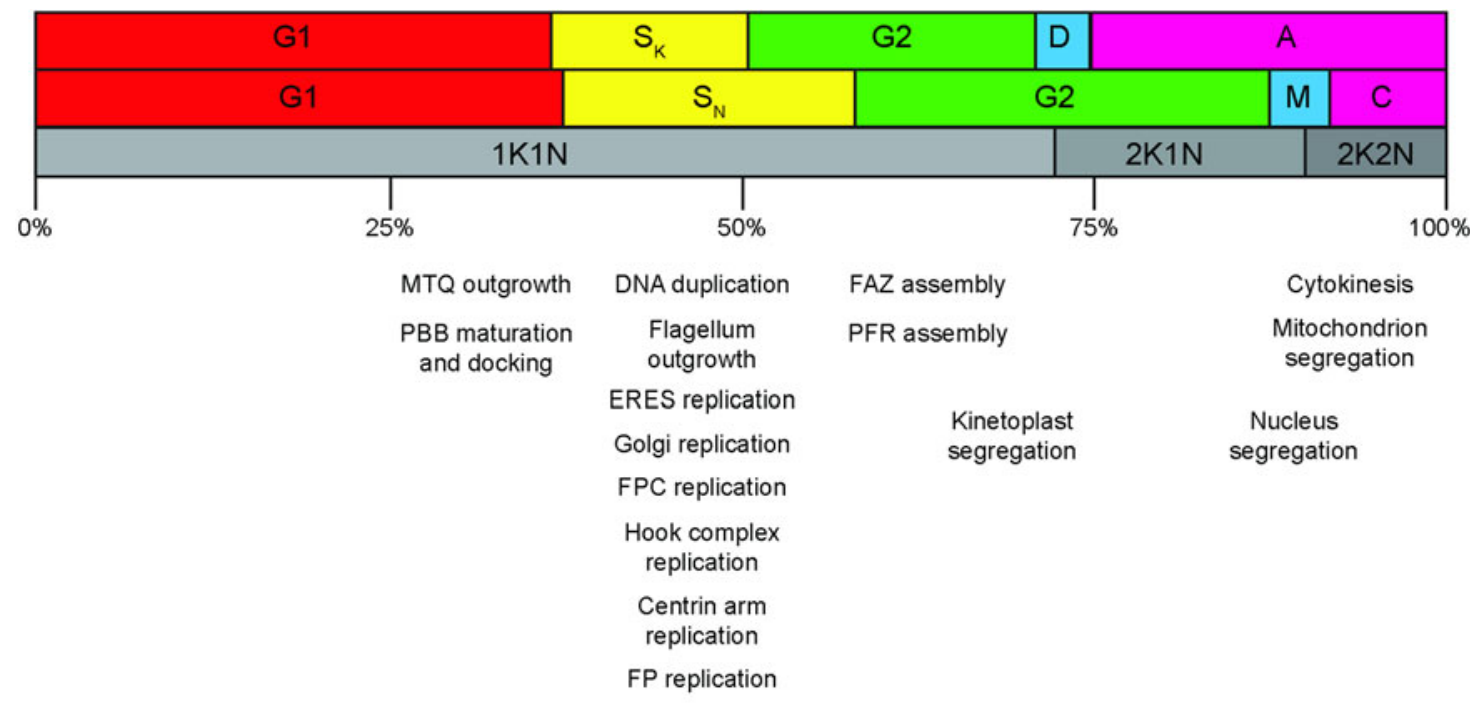

Not depicted: endoplasmic reticulum, endosomes, lysosome, glycosomes, acidocalcisomes

Fig. 2. Cell division cycle progression and the replication of cellular structures and organelles. Top row: cell cycle phases for the kinetoplast. Canonical G1, S, G2 cell cycle phases are shown, along with the division period (D) and post-division period (A). Middle row: cell cycle phases for the nucleus. M, mitosis; C, cytokinesis period. Note that C includes both the post-mitotic phase and the actual cell cleavage period. Cell cleavage accounts for less than half of the total C period. The notation used in the top and middle rows is the standard 1990 terminology (Woodward and Gull, 1990). Bottom row: cell cycle classifications according to $\mathrm{K} / \mathrm{N}$ counts. The approximate progression time through the whole cell cycle is indicated in percentages shown underneath. The approximate temporal position of cellular structure and organelle replication events are indicated. MTQ, microtubule quartet; PBB, probasal body; ERES, endoplasmic reticulum exit site; FPC, flagellar pocket collar; FP, flagellar pocket; FAZ, flagellum attachment zone; PFR, paraflagellar rod.

asynchronously, and methods of synchronizing them remain somewhat time-consuming and inefficient. In the following sections, the existing methods for cell division cycle analysis and cell synchronization of T. bruce $i$ will be summarized. This will be followed by a consideration of candidate methods for global analysis of the trypanosome cell division cycle, and the contribution that automated, high-throughput analysis can make. Finally, a new tool to unify these approaches is proposed: in silico synchronization (ISS).

\section{CELL DIVISION CYCLE ANALYSIS IN T.BRUCEI}

\section{The cell biology pipeline}

Cell division cycle analysis in T. brucei is typically carried out to characterize the effect of depletion of a protein of interest. Depletion is usually carried out using RNAi directed against the target protein, or through construction of a conditional knockout cell line in which a single ectopic allele is under regulated and inducible expression (Wirtz et al. 1999; LaCount et al. 2000; Wang et al. 2000; Alibu et al. 2005) (Fig. 3). After the generation of the required genetically modified cell line, it is vital that a number of control experiments are carried out and reported in order to verify its genotype and properties. These include confirming the integration of targeting constructs at the intended loci, confirming the expression, expression level and localization of any ectopic protein, and determining the kinetics of expression or depletion of the protein of interest (Fig. 3). Following validation of the cell line, the first step in its analysis is to assay for a growth defect upon modulation of the protein of interest, and select a timepoint or timepoints for further investigation. The choice of timepoint is made based on knowledge of the growth data and the level of protein depletion at that moment. Having identified the timepoint for analysis, the relative numbers of cells in different cell cycle states will be quantified using DNA labelling. Kinetoplast and nuclear DNA are labelled using DNA dyes such as DAPI or Hoechst, and the cells examined using either fluorescence microscopy or flow cytometry. Microscopic analysis of the cells allows the quantification of cells with one or two kinetoplasts $(\mathrm{K})$ and one or two nuclei $(\mathrm{N})$. The ordered progression of the cell division cycle, in which kinetoplast segregation precedes nuclear division, allows the easy partitioning of the cycle into three normal states: $1 \mathrm{~K} 1 \mathrm{~N}$, $2 \mathrm{~K} 1 \mathrm{~N}$ and $2 \mathrm{~K} 2 \mathrm{~N}$. Accumulation of cells in one state or the appearance of cells with abnormal $\mathrm{K} / \mathrm{N}$ numbers (for example, $1 \mathrm{~K} 0 \mathrm{~N}, 0 \mathrm{~K} 1 \mathrm{~N}$ and $1 \mathrm{~K} 2 \mathrm{~N}$ ) is immediately indicative of a possible cell division cycle effect. This approach has the advantage of decent resolution but is often done manually and is 


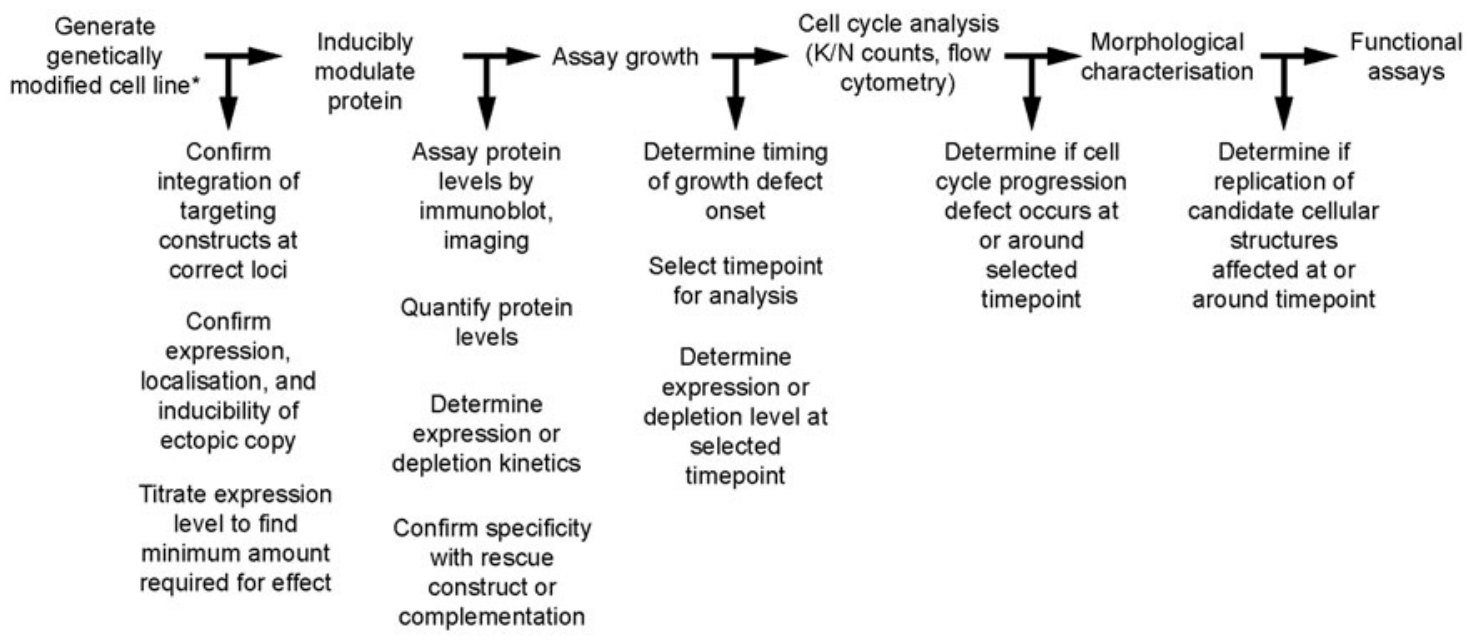

${ }^{\star} \mathrm{RNAi}$, conditional knockout (CKO), gene deletion, ectopic overexpression.

Fig. 3. The cell biology pipeline. A generalized pipeline for the molecular cell biology analysis of a genetically modified cell line is shown. The pipeline is principally written for analysis of an RNAi or conditional knockout (CKO) cell line, but is applicable also to gene deletion and ectopic overexpression cell lines. Not every control is applicable for every type of cell line. Note that this assumes that the localization of the target protein has already been validated.

thus very labour intensive. Flow cytometry, while faster and more automated, permits only the sorting of G1/S and G2/M proportions of the cell cycle and the asynchrony of trypanosome populations further limits its resolution. Monitoring the actual duplication of DNA using for example $\mathrm{BrdU}$ is typically not considered unless replication of nuclear or kinetoplast material is the main focus of the project (Robinson and Gull, 1994).

A much greater problem, common to both approaches, is that the majority of the cell biological events associated with the cell division cycle - replication of the basal body, Golgi, ER exit site, flagellar pocket, flagellar pocket collar - are completed in the interval between the $1 \mathrm{~K} 1 \mathrm{~N}$ and $2 \mathrm{~K} 1 \mathrm{~N}$ states (Fig. 2). Around $70 \%$ of the cells in an asynchronous population of $T$. brucei will be $1 \mathrm{~K} 1 \mathrm{~N}$, yet this category covers everything from interphase cells, which have just completed cytokinesis, to cells with an almost completely replicated complement of organelles (Archer et al. 2011). Greater consideration of the cell biological states that lie between $1 \mathrm{~K} 1 \mathrm{~N}$ and $2 \mathrm{~K} 1 \mathrm{~N}$ cells is clearly needed.

Next, or coincident with the microscopic analysis of $\mathrm{K} / \mathrm{N}$ states, is morphological characterization of the cells. At its most basic this involves imaging of live or fixed cells using transmitted light to determine whether there are any obvious abnormal phenotypic effects - partially or wholly detached flagella, enlarged flagellar pockets, impaired motility, and accumulation of cells showing arrested or impaired cytokinesis are a number of the most common examples. Further characterization can be accomplished using indirect immunofluorescence analysis with antibodies specific for various cellular structures or organelles. These assays allow determination of whether the duplication and/or segregation of major cellular features is affected; tabulation of these observations alongside the $\mathrm{K} / \mathrm{N}$ counts can generally allow a rough estimation of where in the cell division cycle things begin to go awry. An important control is confirmation that the affected cells do indeed have lower levels of the target protein so that morphological changes can be directly correlated with impaired function.

It is vitally important that such assays are carried out as soon as phenotypic effects become manifest, ideally at or just before the point when the affected population begins to exhibit a growth defect. The seeming lack of some cell cycle checkpoints in $T$. brucei means that impaired cells almost never arrest at a particular stage - instead, organelle and DNA replication continues unabated in the absence of cell division, leading to the generation of polyploid 'monster' cells with multiple organelles and flagella. It is impossible to infer the original defect in such cells and the phenotypes are not informative. Only by determining what are the primary effects of a protein's loss can its likely function be inferred with any degree of confidence, and even then teasing apart direct and indirect effects can be challenging (Hammarton et al. 2007).

Once the morphological characterization is complete and an appropriate timepoint or timepoints for analysis have been determined, functional assays must be utilized (Fig. 3). These allow specific hypotheses concerning the protein's function to be tested. The wide availability of reverse genetics tools facilitating the deletion, overexpression, mutation, and 
truncation of genes in T. brucei is a distinct advantage of the system.

This morphological and functional characterization is extremely labour intensive and additionally carries a very large element of bias - only candidate structures/organelles are interrogated, so discovering unexpected phenotypic consequences of protein depletion (such as might be revealed in genetic suppressor screens) are not possible. The choice of timepoint is likewise subjective. An additional problem comes in the quantification of such assays. There exists no common standard for the conduct of these experiments, and the number of independent experiments (ideally at least three) is not always disclosed. Quantification is often carried out manually. Detailed understanding of statistics is not widespread in the life sciences, and the misuse of $P$-values to infer whether a result is real or not is as frequent here as elsewhere. For detailed practical recommendations on the proper processing and presentation of quantitative datasets, the reader is referred to the following articles: Cumming et al. 2007; Vaux, 2014; Klaus, 2016; Weissgerber et al. 2016. Undersampling (which compromises interpretation) and oversampling (which reduces efficiency) are also problems.

\section{Cell synchronization in T. brucei}

The asynchronous growth of T. brucei populations has long been an impediment for accurate cell division cycle analysis. There appears to be small stochastic variation in the cell division cycle length in individual cells, resulting in a passive asynchronization of cell division cycle progression at a population level. Consequently, determining what are the primary effects of a protein's loss is made extremely difficult by the fact that such loss is initiated simultaneously in cells covering all stages of the cell cycle. Additionally, the depletion kinetics are slow and specific to individual proteins. In both RNAi and conditional knockouts, protein depletion depends on mRNA degradation or transcription cessation, followed by gradual protein loss as the target is turned over according to its intrinsic half-life. Mitotically-regulated proteins will exhibit very fast depletion as they are naturally degraded each cell cycle; most other proteins often exhibit very slow depletion as they are more stable, in general far more stable than their mRNAs. Thus, determining a protein's likely function currently requires consideration of how quickly it is simultaneously being lost from cells at each stage of the cell cycle - a task that is complex in the extreme.

To date, four main approaches have been utilized for synchronization of T. brucei, which will be considered in the following paragraphs. They are:

- starvation-induced,

- hydroxyurea-mediated,
- Vybrant DyeCycle,

- elutriation.

Starvation-induced synchronization is the simplest of the protocols. It requires growing cells to stationary phase, and then releasing them by dilution into fresh media (Gale et al. 1994). The absence of drugs or other manipulation is a plus, although allowing the cells to accumulate in stationary phase may carry its own set of consequences, as noted below. The cells do not achieve full synchrony, with a majority accumulating at G1, but a small number are still in G2/M phases (Gale et al. 1994; Archer et al. 2009, 2011). Upon release, the cells remain semi-synchronous for around $12 \mathrm{~h}$, then resume asynchronous proliferation. Despite its simplicity, the principle drawbacks of this method are the incomplete synchronization achieved, the likelihood that the 'synchronization' is actually a recovery phase, and the high degree of variation between replicates (Archer et al. 2011). Starvation is also known to induce the formation of stress granules (Cassola et al. 2007; Fritz et al. 2015). The protocol has been almost exclusively applied to procyclic form cells. Use of starvation in bloodstream form cells has not been intensively pursued, although there are indications that some cell arrest occurs (Morgan et al. 1993). However, growing pleomorphic cell lines to stationary phase will induce the formation of stumpy cells, and in monomorphic cell lines a pseudo-stumpy morphology is produced. For the reasons mentioned above, the use of starvation-induced synchronization cannot be recommended.

Hydroxyurea-mediated synchronization has probably been the most popular of the techniques to date. Hydroxyurea inhibits ribonucleotide reductase, one of the enzymes involved in the synthesis of dNTPs (Hofer et al. 1997). The drop in cellular dNTP levels inhibits DNA replication, causing cells initiating or undergoing S-phase to accumulate. Early work using hydroxyurea on procyclic and bloodstream from $T$. brucei was discouraging however, with population growth being inhibited but DNA synthesis apparently not (Brun, 1980; Mutomba and Wang, 1996). This approach was revisited by the Englund laboratory in 2008, and a protocol for successful synchronization was reported (Chowdhury et al. 2008). The protocol was rapidly adapted for bloodstream form cells, with similar results (Forsythe et al. 2009). The exact mechanism remains unclear, as kinetoplast $\mathrm{S}$-phase is completed while nuclear division is strongly inhibited, leading to an accumulation of $2 \mathrm{~K} 1 \mathrm{~N}$ cells. Synchronization is thus achieved by slowing progression through the cell cycle, rather than arresting it. Once released from the block by hydroxyurea washout, the cells synchronously progress through the remainder of the cell cycle, before gradually becoming asynchronous over 
the course of the subsequent cycle. The hydroxyurea protocol is simple and appears to be nontoxic; however, its principle drawback is the relatively late stage at which cell cycle slowdown occurs $-2 \mathrm{~K} 1 \mathrm{~N}$. Most organelle and cellular structure replication has already occurred at this stage, which greatly limits the utility of the protocol for studying earlier events in the cell division cycle (Fig. 2). The relatively short time period in which the cells remain synchronized limits the opportunity for analysis. The use of chemical treatments generally to synchronize cells has been discouraged (Shedden and Cooper, 2002). The principle objection to chemical (or starvation)induced synchronization is that it is often not clear that true synchronization has been achieved. Furthermore, the treatment may itself alter gene expression patterns.

Vybrant DyeCycle protocols are not true synchronization methods but instead produce selective enrichment of different cell cycle states. They involve the use of commercial DNA dyes (Thermo Fisher Scientific) coupled with fluorescence-activated cell sorting of the labelled cells. Vybrant DyeCycle Orange has been successfully used in procyclic cells (Siegel et al. 2008a, b). Vybrant DyeCycle Violet was subsequently used in bloodstream form cells (Kabani et al. 2010). Despite their simplicity and applicability to both procyclic and bloodstream form cells, the protocols are yet to be widely-adopted by the trypanosome research community. One key drawback is low yield, which reduces the number of cells available for downstream analysis. Arguably more important though is the low resolution afforded by fluorescence-activated cell sorting of $T$. brucei. In T. brucei, nuclear S-phase initiates before segregation of the duplicated kinetoplast DNA (Woodward and Gull, 1990; Siegel et al. 2008b; Kabani et al. 2010). Thus, selection of G1 cells will yield a mixed population of 'true' $1 \mathrm{~K} 1 \mathrm{~N}$ cells in which kinetoplast duplication has not yet begun, and late $1 \mathrm{~K} 1 \mathrm{~N}$ cells in which kinetoplast duplication is almost complete. As noted earlier, replication of many cytoplasmic organelles will already have occurred within this window (Fig. 2). Similarly, selection of G2/M cells yields a mixed population of late $1 \mathrm{~K} 1 \mathrm{~N}$ cells, $2 \mathrm{~K} 1 \mathrm{~N}$ cells and $2 \mathrm{~K} 2 \mathrm{~N}$ cells. However, probably the principle objection is that the effect on the cells after labelling with the dye and sorting is unclear, with bloodstream form cells showing a significant delay in growth rates after the procedure (Kabani et al. 2010). The effect of the dye on cell division cycle progression in procyclic cells post-sorting has not been reported.

Elutriation is a mechanical process in which cells are sorted on the basis of size and density using a counterflow mechanism. Centrifugal forces are used to sediment cells towards the outer edge of an elutriation chamber, while an inward flow of buffer solution produces a counterflow drag force that selectively sorts cells within the population towards the centre of the chamber. By modulating the centrifugal force and buffer flow, different sizes of particles can be eluted from the chamber according to their individual sedimentation properties. A 'doublecut' elutriation (DCE) protocol was recently developed in a landmark paper from the Clayton laboratory (Archer et al. 2011). This protocol involves first sorting an asynchronous population to obtain the largest set of cells - i.e. cells at a relatively late stage of the cell division cycle and soon to undergo cytokinesis. These cells are then cultured for around $1 \mathrm{~h}$, and subsequently subjected to a second round of elutriation. The brief incubation period allows time for the cells to undergo cytokinesis, and the second round of elutriation allows selection of the smallest cells, namely those in early G1 phase. The cells remain synchronized for around one cell cycle, and progress through the replication process at a normal rate. A crucial advantage of this protocol is that it allows analysis of the earliest events in the cell division cycle, unlike the hydroxyurea protocol. It also requires no chemical treatment, and although the approximate yield from the original population input is only $5 \%$ it can be scaled up easily. To date, the protocol has been applied in two elegant studies of the mitotic kinase TbPLK (Lozano-Núñez et al. 2013; McAllaster et al. 2015). In the first, the DCE protocol was combined with the use of an analogue-sensitive TbPLK to provide rapid and specific inhibition of kinase activity at different stages of the cell cycle, and consequent dissection of the requirements for TbPLK at those time points. The follow-up work combined the DCE and analogue-sensitive TbPLK approach with proteomics in order to identify putative binding partners and substrates of the enzyme. The DCE protocol clearly represents the best of the available protocols for cell synchronization in $T$. brucei, and the only one that is really compatible with biochemical and proteomic analysis. However, its main drawback is that to date it has been used solely on procyclic cells and it remains unclear whether it can be used for bloodstream form ones (Archer et al. 2011). The smaller size of bloodstream form cells relative to procyclic ones may impair their effective sorting in the procedure.

In summary, of the available protocols for cell synchronization in $T$. brucei described to date, none represents a truly optimal solution. Only DCE is able to produce synchronized populations of cells at early G1 phase, which progress through the cell cycle without an abnormal delay, and at present this technique has been optimized for procyclic cells only. None of the protocols is able to yield a population of cells that remain synchronized for longer than one cell division cycle. This latter fact already makes synchronization somewhat 
refractory to RNAi or conditional knockout approaches, as the depletion kinetics are too slow. Moreover, the rapid desynchronization of the artificially-synchronized cells is consistent with an intrinsic variation in the timing of cell cycle initiation and/ or progression between individual cells in a clonal population. This stochasticity in the timings must have a biological, and possibly also an adaptive, reason. This begs the question as to whether artificial synchronization should be performed at all, despite its utility.

APPROACHES FOR GLOBAL CELL ANALYSIS IN T. BRUCEI

Independent of whether cell synchronization is used or not, there remains a pressing need for a more global approach to cell division cycle analysis in T. brucei. As noted earlier, the focus on individual proteins that is typical of current cell biology approaches carries an inherent element of bias that may blind observers to unexpected effects. Two types of technique offer a degree of redress to this problem.

\section{Electron microscopy-based techniques (tomography, serial block face)}

Two electron microscopy-based techniques - electron tomography and serial block-face scanning electron microscopy (SBF-SEM) - both present excellent solutions to the global analysis problem (Gluenz et al. 2015). Both techniques carry the enormous advantages of very high resolution and unbiased acquisition of data from all contraststained cellular structures and organelles simultaneously. Dual-axis electron tomography utilizes thick sections that are tilted in $1^{\circ}-2^{\circ}$ increments through a total path of around $120^{\circ}-140^{\circ}$. Rotating the section through $90^{\circ}$ allows the subsequent collection of data along an orthogonal axis, and the datasets can then be combined and aligned computationally to generate a three-dimensional image of the sampled cellular volume. SBF-SEM involves mounting an entire embedded sample within a SEM equipped with a diamond knife (Denk and Horstmann, 2004). The face of the block is imaged, and then sliced off with the knife. Sequential iteration of this process results in data acquisition through a large sample volume composed of many (hundreds or thousands) ultrathin sections. The two techniques are compatible in that sample preparation is the same. Separately and together, they have already resulted in a number of seminal papers on trypanosome morphology and ultrastructure, with the Vaughan laboratory's discovery of a cell surface groove guiding flagellum biosynthesis in bloodstream form cells a particular highlight (Hughes et al. 2013).
The principle drawbacks of both methods are the extremely demanding technical requirements in terms of both hardware and training. The hardware is expensive and specialized, which necessitates a considerable degree of institutional investment; sample preparation times - which will impact the quality of the data - are also relatively long. The need for advanced training and a period for the acquisition of tacit knowledge and experience mean that both techniques are off-limits to non-specialists. Tomography has a fairly small sampling volume, and the generation of a large number of independent datasets is very time-consuming.

\section{Fluorescence microscopy approaches}

Fluorescence microscopy approaches are almost a counterpoint to the electron microscopy-based ones. The principle advantages of fluorescence microscopy are its short preparation time, and lower (although still not insignificant) technical costs. A key advantage relative to electron microscopy is the ability to observe live cells - chemical fixation can introduce artefacts, and the dehydration and plastic embedding steps required for many electron microscopy protocols causes cells to shrink. This makes the analysis of fixed cells (unavoidable for electron microscopy) ultimately less accurate for some morphological parameters, particularly cell length. Recent advances in super-resolution imaging offer the opportunity to close the gap on electron microscopy in terms of resolution, although these techniques are not for casual users. The main disadvantages of fluorescence microscopy approaches stem from its lower resolution compared with electron microscopy, and its requirement for the use of labels (either dyes, protein tags or antibody conjugates), which result in the selective illumination of one or only a small number of cellular structures. This unavoidably introduces an element of bias to the experiment design. In addition, its easy availability has resulted in a proliferation of protocols with consequently little standardization across the field and published data that are not always in agreement. A recent example are the two reported localizations for the phospholipid phosphatidylinositol-(4,5)-bisphosphate (Demmel et al. 2014; Cestari and Stuart, 2015). One paper reported a predominant localization at the flagellar pocket membrane; the other a diffuse localization throughout the plasma membrane and flagellar membrane. Publication of experiment metadata is not standard, and there are few enforced community standards for crucial procedures such as colocalization.

Both fluorescence and electron microscopy-based techniques allow a focus on cellular organelles and structures rather than individual proteins. While delineating the structure and function of individual proteins remains the ultimate goal of the reductionist 
approach to cell biology, proteins are generally not visible unless present in large complexes or macromolecular arrays. The higher visibility of organelles makes them a more appropriate focus, particularly in the context of analysing cell division cycle progression and phenotypes associated with it. It is worth noting too that correlated light and electron microscopy (CLEM) approaches potentially offer the best of both worlds.

In terms of scientific progression, an additional burden is the fact that work is currently carried out in multiple labs spread across disparate geographical locations. This results in an overall low efficiency in terms of rate of progress, and would benefit from ongoing studies being better able to bootstrap onto the conclusions of prior ones - more communitylevel organization, in other words. In this respect, the relatively small size and high interactivity of the $T$. brucei research network represents a distinct though relatively untapped advantage. Recent and ongoing community-level projects at different scales such as TriTrypDB and the Tryp'Tag initiative offer encouraging signs that this nascent potential is beginning to be realized (Aslett et al. 2010; Dean et al., 2016; Tryp'Tag, 2016).

\section{AUTOMATED CELL CYCLE ANALYSIS}

Automated cell cycle analysis of $T$. brucei was pioneered in 2012 by the Gull laboratory, using a DNA double-staining technique and colour deconvolution method (Wheeler et al. 2012). The two DNA stains - DAPI, and propidium iodide or SYBR green - bind by interacting with the minor groove or intercalating between the base pairs, respectively. The method takes advantage of the different AT content of the kinetoplast and nuclear DNA, and the higher affinity of minor groove-binding dyes such as DAPI for AT-rich DNA. Consequently, the signals from the kinetoplast and the nuclear DNA can be distinguished based on their relative intensity. The highthroughput algorithm for automated image analysis developed using this labelling technique is capable of classifying asynchronous populations of T. brucei according to their cell cycle state (whether canonical or aberrant), and also provides information on cell length, width and shape based on phase contrast data. Importantly, the paper also provides a comparison between flow cytometry, manual counting and the algorithm in terms of accuracy. The methods all have a similar accuracy and precision, with flow cytometry the most precise and manual counting the least precise. However, flow cytometry is not capable of separately quantifying nucleus and kinetoplast DNA, which the other two approaches can do (Wheeler et al. 2012). Despite its obvious utility, there has been to date only one published instance of its application in
T. brucei (Trindade and Rijo-Ferreira et al. 2016). The reasons for this are not clear, although the algorithm's requirement for high-quality phase contrast images may be a factor. It may also simply represent the time required for a new method to percolate into the standard toolbox of a research community. One possibility however is that the requirement for two DNA stains, when one is the de facto standard, introduces something of an activation energy barrier for adoption of the technique.

Besides the improvements in terms of reducing observer bias and increasing throughput, automated analysis carries another and potentially transformative benefit - the opportunity to derive cell division cycle progression from asynchronously-growing populations. A recent theoretical paper from Richard Wheeler on the ergodic principle makes this implication explicit (Wheeler, 2015). Ergodicity (from the Greek words 'ergon' meaning 'work', and 'odos' meaning 'path') was coined by Ludwig Boltzmann in the late 19th century as part of his work on statistical mechanics. In general terms, it describes dynamic systems in which the ensemble behaviour of the components of that system at one point in time (i.e. a snapshot) is similar to the behaviour of a single component of the system over a timecourse. This matches the behaviour of growing microbial populations - asynchronous cell cultures are in a quasi-steady state, with the proportions of cells in a particular category (for example, $1 \mathrm{~K} 1 \mathrm{~N}, 2 \mathrm{~K} 1 \mathrm{~N}$ and $2 \mathrm{~K} 2 \mathrm{~N}$ ) remaining approximately constant over time. This is due to the fact that the number of cells in each category will be directly related to the time spent in that state. However this also requires accounting for the effect of binary fission - the production of two daughter cells entails the 'loss' of one mother cell, so there are always twice as many cells entering the next cell cycle as there are ones undergoing the previous one. This results in an overrepresentation of early cell cycle events in the population, but can be easily adjusted for mathematically. Furthermore, cells progress from one category to the next in an ordered sequence $(1 \mathrm{~K} 1 \mathrm{~N}$ progresses to $2 \mathrm{~K} 1 \mathrm{~N}$, which progresses to $2 \mathrm{~K} 2 \mathrm{~N}$ ). As such, asynchronous populations contain information on all stages of the cell division cycle simultaneously, and static images of these populations are more information-rich than single images of synchronized cells. For a more detailed explanation of the weak and strong ergodic assumptions that such analyses require, the reader is directed to the article mentioned earlier (Wheeler, 2015). The mathematics underpinning the disentanglement of such datasets has been established for more than forty years, but has only recently begun to be applied to quantitative cell biology (Kafri et al. 2013). The continuing advances in computing power that have become available to the scientific community over the last decade or so now make it possible to envision a new approach in 
T. brucei cell division cycle analysis, which we here refer to as 'ISS'.

\section{IN SILICO SYNCHRONIZATION}

ISS would represent a fast, simple, and cost-effective solution to cell division cycle analysis that fulfils all of the requirements articulated above. By using multiple continuous variables (initially DNA content and flagellum length) and ergodic analysis, it will be possible to provide a precise timeline for cell cycle progression such as has already been achieved in Leishmania (Wheeler et al. 2011). This timeline can be derived from asynchronously-replicating populations and thus permits a fast and ISS without the need for chemical treatments or labourintensive handling. The use of computational methods also means that the populations can be observed for as long as wished, without the short time windows engendered in current synchronization protocols by the rapid loss of synchrony.

Importantly, once this timeline has been established, it will enable the addition of further parameters with increasing ease. Morphological details such as cell length, width, surface area and volume (obtained using fluorescence labelling of the cell plasma membrane) can be integrated by bootstrapping observations of their variability in asynchronous populations alongside one of the prior variables (DNA content, flagellum length). Automated analysis will increase throughput and standardize quantitation of the data. Fluorescence labelling of different organelles (using immunofluorescence, fluorescent protein-tagged reporters and fluorophore-conjugated cargo molecules) can then add successive layers of detail in order to gradually provide an unbiased overview of the replication of all cellular organelles and structures. The drawbacks in fluorescence labelling noted in the section above can be compensated for by the ease and speed of data acquisition. ISS would by no means be incompatible with the use of SBF-SEM or even electron tomography - these techniques could improve the resolution still further.

The progressive accumulation of time-indexed replication of cellular organelles and structures should eventually make the generation of a full mathematical model for the T. brucei cell division cycle feasible. This standardized in silico cell would permit interrogation of a number of issues that are currently challenging. These would include but not be restricted to: the interplay between organelles during their replication; the relative timing of events during the cell cycle; finer temporal resolution of rapid events; delineation of membrane-membrane contacts between organelles.

Intuitively, the model would be compatible with analysis of both RNAi phenotypes and drug treatments. ISS of RNAi-induced or drug-treated populations using only DNA labelling would pinpoint with high temporal resolution the exact stage of the cell division cycle at which a phenotype begins to become manifest, though it should be noted that accounting for the depletion kinetics inherent to RNAi will be computationally challenging. Reference to the in silico cell would enable identification of the cellular organelles undergoing replication at that time point and other putativelyaffected cellular processes. This should make the analysis of pleiotropic phenotypes far more feasible than is currently the case. Standard reverse genetics analysis of the RNAi phenotypes associated with individual proteins will be enriched by knowledge of the cell cycle behaviour of the structures and organelles they are associated with.

Ultimately, it is possible to envisage the in silico cell generated from accumulated ISS data becoming an online portal for community-level use and annotation. This would allow the rapid integration of additional datasets and ongoing refinement, with no alteration to existing lab protocols required. As noted previously, the relatively small size of the $T$. brucei research community and its high level of interactivity and communication make this an achievable goal that would be more difficult for less social fields.

\section{Concluding remarks}

In this review, the existing methods for cell division cycle analysis and synchronization in $T$. brucei have been summarized and evaluated. Techniques for global cell analysis have been compared, and the promise offered by automated and high-throughput computational methods highlighted. The adoption of ISS as a new tool for cell division cycle analysis has been advocated. The advent of single-cell transcriptomics (and potentially even proteomics) is a parallel development that will also enable the analysis of asynchronous populations. By taking advantage of ongoing advances in computational biology, this perhaps offers an unprecedented opportunity for hearing trypanosome bodies talk.

\section{ACKNOWLEDGEMENTS}

The authors would like to thank Susanne Kramer and Tim Krüger (both University of Würzburg) for feedback on the manuscript. We apologise to authors whose work was not cited owing to space restrictions.

\section{FINANCIAL SUPPORT}

Work in B.M.'s laboratory is supported by the Austrian Research Fund (FWF) grant P27016-B21; work in M.E.'s laboratory is supported by the Deutsche Forschungsgemeinschaft (DFG) grants EN 305, the Sonderforschungsbereich 630, the German-African Cooperation Programme in Infectology, the GRK 2157 
and the SPP1726. M.E. is a member of the Wilhelm Conrad Röntgen-Center for Complex Material Systems (RCCM).

\section{REFERENCES}

Alibu, V. P., Storm, L., Haile, S., Clayton, C. and Horn, D. (2005). A doubly inducible system for RNA interference and rapid RNAi plasmid construction in Trypanosoma brucei. Molecular and Biochemical Parasitology 139, 75-82.

Archer, S. K., Luu, V. D., de Queiroz, R. A., Brems, S. and Clayton, C. (2009). Trypanosoma brucei PUF9 regulates mRNAs for proteins involved in replicative processes over the cell cycle. PLoS Pathogens 5, e1000565.

Archer, S. K., Inchaustegui, D., Queiroz, R. and Clayton, C. (2011). The cell cycle regulated transcriptome of Trypanosoma brucei. PLoS ONE 6, e18425.

Aslett, M., Aurrecoechea, C., Berriman, M., Brestelli, J., Brunk, B. P., Carrington, M., Depledge, D.P., Fischer, S., Gajria, B., Gao, X., Gardner, M. J., Gingle, A., Grant, G., Harb, O. S., Heiges, M., HertzFowler, C., Houston, R., Innamorato, F., Iodice, J., Kissinger, J. C., Kraemer, E., Li, W., Logan, F. J., Miller, J. A., Mitra, S., Myler, P. J., Nayak, V., Pennington, C., Phan, I., Pinney, D. F., Ramasamy, G., Rogers, M. B., Roos, D.S., Ross, C., Sivam, D., Smith, D.F., Srinivasamoorthy, G., Stoeckert, C. J., Jr., Subramanian, S., Thibodeau, R., Tivey, A., Treatman, C., Velarde, G. and Wang, H. (2010). TriTrypDB: a functional genomic resource for the Trypanosomatidae. Nucleic Acids Research 38(Database issue), D457-D462. Bangs, J. D. (2011). Replication of the ERES: Golgi junction in bloodstream-form African trypanosomes. Molecular Microbiology 82, 1433-1443. Berthier, D., Brenière, S. F., Bras-Gonçalves, R., Lemesre, J. L., Jamonneau, V., Solano, P., Lejon, V., Thévenon, S. and Bucheton, B. (2016). Tolerance to trypanosomatids: a threat, or a key for disease elimination? Trends in Parasitology 32, 157-168.

Briggs, L. J., McKean, P. G., Baines, A., Moreira-Leite, F., Davidge, J., Vaughan, S. and Gull, K. (2004). The flagella connector of Trypanosoma brucei: an unusual mobile transmembrane junction. Fournal of Cell Science 117, 1641-1651.

Brun, R. (1980). Hydroxyurea: effect on growth, structure, and [3H]thymidine uptake of Trypanosoma brucei procyclic culture forms. Fournal of Protozoology 27, 122-128.

Caljon, G., Van Reet, N., De Trez, C., Vermeersch, M., PérezMorga, D. and Van Den Abbeele, J. (2016). The dermis as a delivery site of Trypanosoma brucei for tsetse flies. PLoS Pathogens 12, e1005744.

Capewell, P., Cren-Travaillé, C., Marchesi, F., Johnston, P., Clucas, C., Benson, R. A., Gorman, T.A., Calvo-Alvarez, E., Crouzols, A., Jouvion, G., Jamonneau, V., Weir, W., Stevenson, M. L., O'Neill, K., Cooper, A., Swar, N. K., Bucheton, B., Ngoyi, D. M., Garside, P., Rotureau, B. and MacLeod, A. (2016). The skin is a significant but overlooked anatomical reservoir for vector-borne African trypanosomes. Elife Sep 22;5. pii: e17716. doi: 10.7554/eLife.17716. Cassola, A., De Gaudenzi, J. G. and Frasch, A. C. (2007). Recruitment of mRNAs to cytoplasmic ribonucleoprotein granules in trypanosomes. Molecular Microbiology 65, 655-670.

Cestari, I. and Stuart, K. (2015). Inositol phosphate pathway controls transcription of telomeric expression sites in trypanosomes. Proceedings of the National Academy of Sciences of the United States of America 112, E2803-E2812.

Chowdhury, A. R., Zhao, Z. and Englund, P. T. (2008). Effect of hydroxyurea on procyclic Trypanosoma brucei: an unconventional mechanism for achieving synchronous growth. Eukaryotic Cell 7, 425-428.

Cumming, G., Fidler, F. and Vaux, D. L. (2007). Error bars in experimental biology. Fournal of Cell Biology 177, 7-11.

Davidge, J.A., Chambers, E., Dickinson, H.A., Towers, K., Ginger, M. L., McKean, P. G. and Gull, K. (2006). Trypanosome IFT mutants provide insight into the motor location for mobility of the flagella connector and flagellar membrane formation. Fournal of Cell Science 119, 3935-3943

Dean, S., Sunter, J. D. and Wheeler, R. J. (2016). Tryp Tag.org: a trypanosome genome-wide protein localisation resource. Trends in Parasitoogy. doi: 10.1016/j.pt.2016.10.009

Demmel, L., Melak, M., Kotisch, H., Fendos, J., Reipert, S. and Warren, G. (2011). Differential selection of Golgi proteins by COPII Sec24 isoforms in procyclic Trypanosoma brucei. Traffic 12, 1575-1591.

Demmel, L., Schmidt, K., Lucast, L., Havlicek, K., Zankel, A., Koestler, T., Reithofer, V., de Camilli, P. and Warren, G. (2014). The endocytic activity of the flagellar pocket in Trypanosoma brucei is regulated by an adjacent phosphatidylinositol phosphate kinase. Fournal of Cell Science 127, 2351-2364. Erratum in: Fournal of Cell Science 129(11), 2285
Denk, W. and Horstmann, H. (2004). Serial block-face scanning electron microscopy to reconstruct three-dimensional tissue nanostructure. PLoS Biology 2, e329.

Drugs for Neglected Diseases Initiative. (2016). From Neglected Diseases to Neglected Patients and Populations. 2015 Annual Report. Drugs for Neglected Diseases Initiative, Geneva, Switzerland.

Echodu, R., Sistrom, M., Bateta, R., Murilla, G., Okedi, L., Aksoy, S., Enyioha, C., Enyaru, J., Opiyo, E., Gibson, W. and Caccone, A. (2015). Genetic diversity and population structure of Trypanosoma brucei in Uganda: implications for the epidemiology of sleeping sickness and Nagana. PLoS Neglected Tropical Diseases 9, e0003353.

Engstler, M., Thilo, L., Weise, F., Grünfelder, C. G., Schwarz, H., Boshart, M. and Overath, P. (2004). Kinetics of endocytosis and recycling of the GPI-anchored variant surface glycoprotein in Trypanosoma brucei. Fournal of Cell Science 117, 1105-1115. Erratum in: Journal of Cell Science 2004 117(Pt 16), 3703.

Ersfeld, K. and Gull, K. (1997). Partitioning of large and minichromosomes in Trypanosoma brucei. Science 276, 611-614.

Esson, H. J., Morriswood, B., Yavuz, S., Vidilaseris, K., Dong, G. and Warren, G. (2012). Morphology of the trypanosome bilobe, a novel cytoskeletal structure. Eukaryotic Cell 11, 761-772. Erratum in: Eukaryotic Cell 2012 11(10):1302

Forsythe, G. R., McCulloch, R. and Hammarton, T. C. (2009). Hydroxyurea-induced synchronisation of bloodstream stage Trypanosoma brucei. Molecular and Biochemical Parasitology 164, 131-136.

Franco, J. R., Simarro, P.P., Diarra, A. and Jannin, J. G. (2014). Epidemiology of human African trypanosomiasis. Clinical Epidemiology 6, 257-275.

Frevert, U., Movila, A., Nikolskaia, O. V., Raper, J., Mackey, Z. B., Abdulla, M., McKerrow, J. and Grab, D. J. (2012). Early invasion of brain parenchyma by African trypanosomes. PLoS ONE 7, e43913.

Fritz, M., Vanselow, J., Sauer, N., Lamer, S., Goos, C., Siegel, T. N., Subota, I., Schlosser, A., Carrington, M. and Kramer, S. (2015). Novel insights into RNP granules by employing the trypanosome's microtubule skeleton as a molecular sieve. Nucleic Acids Research 43, 8013-8032.

Gale, M., Jr., Carter, V. and Parsons, M. (1994). Cell cycle-specific induction of an $89 \mathrm{kDa}$ serine/threonine protein kinase activity in Trypanosoma brucei. Fournal of Cell Science 107, 1825-1832.

García-Salcedo, J.A., Pérez-Morga, D., Gijón, P., Dilbeck, V., Pays, E. and Nolan, D. P. (2004). A differential role for actin during the life cycle of Trypanosoma brucei. EMBO Fournal 23, 780-789.

Gluenz, E., Povelones, M. L., Englund, P. T. and Gull, K. (2011). The kinetoplast duplication cycle in Trypanosoma brucei is orchestrated by cytoskeleton-mediated cell morphogenesis. Molecular and Cellular Biology 31, 1012-1021.

Gluenz, E., Wheeler, R. J., Hughes, L. and Vaughan, S. (2015). Scanning and three-dimensional electron microscopy methods for the study of Trypanosoma brucei and Leishmania mexicana flagella. Methods in Cell Biology 127, 509-542.

Grünfelder, C. G., Engstler, M., Weise, F., Schwarz, H., Stierhof, Y. D., Morgan, G. W., Field, M. C. and Overath, P. (2003). Endocytosis of a glycosylphosphatidylinositol-anchored protein via clathrin-coated vesicles, sorting by default in endosomes, and exocytosis via RAB11-positive carriers. Molecular Biology of the Cell 14, 2029-2040

Gull, K. (1999). The cytoskeleton of trypanosomatid parasites. Annual Review of Microbiology 53, 629-655.

Gunasekera, K., Wüthrich, D., Braga-Lagache, S., Heller, M. and Ochsenreiter, T. (2012). Proteome remodelling during development from blood to insect-form Trypanosoma brucei quantified by SILAC and mass spectrometry. BMC Genomics $\mathbf{1 3}, 556$

Hammarton, T. C. (2007). Cell cycle regulation in Trypanosoma brucei. Molecular and Biochemical Parasitology 153, 1-8.

Hammarton, T.C., Clark, J., Douglas, F., Boshart, M. and Mottram, J. C. (2003). Stage-specific differences in cell cycle control in Trypanosoma brucei revealed by RNA interference of a mitotic cyclin. Fournal of Biological Chemistry 278, 22877-22886.

Hammarton, T. C., Monnerat, S. and Mottram, J. C. (2007). Cytokinesis in trypanosomatids. Current Opinion in Microbiology 10, 520-527.

He, C. Y., Ho, H. H., Malsam, J., Chalouni, C., West, C. M., Ullu, E., Toomre, D. and Warren, G. (2004). Golgi duplication in Trypanosome brucei. Fournal of Cell Biology 165, 313-321.

Ho, H. H., He, C.Y., de Graffenried, C. L., Murrells, L. J. and Warren, G. (2006). Ordered assembly of the duplicating Golgi in Trypanosoma brucei. Proceedings of the National Academy of Sciences of the United States of America 103, 7676-7681.

Hoare, C. A. and Wallace, F. G. (1966). Developmental stages of Trypanosomatid flagellates: a new terminology. Nature 212, 1385-1386. 
Hofer, A., Schmidt, P.P., Gräslund, A. and Thelander, L. (1997) Cloning and characterization of the R1 and R2 subunits of ribonucleotide reductase from Trypanosoma brucei. Proceedings of the National Academy of Sciences of the United States of America 94, 6959-6964.

Hotez, P. J., Alvarado, M., Basáñez, M. G., Bolliger, I., Bourne, R., Boussinesq, M., Brooker, S. J., Brown, A. S., Buckle, G., Budke, C. M., Carabin, H., Coffeng, L. E., Fèvre, E. M., Fürst, T., Halasa, Y. A., Jasrasaria, R., Johns, N.E., Keiser, J., King, C. H., Lozano, R., Murdoch, M. E., O'Hanlon, S., Pion, S. D., Pullan, R. L., Ramaiah, K. D., Roberts, T., Shepard, D. S., Smith, J. L., Stolk, W. A., Undurraga, E. A., Utzinger, J., Wang, M., Murray, C. J., Naghavi, M. (2014). The global burden of disease study 2010: interpretation and implications for the neglected tropical diseases. PLoS Neglected Tropical Diseases 8, e2865.

Hughes, L., Towers, K., Starborg, T., Gull, K. and Vaughan, S. (2013). A cell-body groove housing the new flagellum tip suggests an adaptation of cellular morphogenesis for parasitism in the bloodstream form of Trypanosoma brucei. Fournal of Cell Science 126, 5748-5757.

Jeffries, T. R., Morgan, G. W. and Field, M. C. (2001). A developmentally regulated rab11 homologue in Trypanosoma brucei is involved in recycling processes. Fournal of Cell Science 114, 2617-2626.

Kabani, S., Waterfall, M. and Matthews, K. R. (2010). Cell-cycle synchronisation of bloodstream forms of Trypanosoma brucei using Vybrant DyeCycle Violet-based sorting. Molecular and Biochemical Parasitology 169, 59-62.

Kafri, R., Levy, J., Ginzberg, M. B., Oh, S., Lahav, G. and Kirschner, M. W. (2013). Dynamics extracted from fixed cells reveal feedback linking cell growth to cell cycle. Nature 494, 480-483.

Klaus, B. (2016). Statistical relevance-relevant statistics, part II: presenting experimental data. EMBO fournal 35, 1726-1729.

Kohl, L., Sherwin, T. and Gull, K. (1999). Assembly of the paraflagellar rod and the flagellum attachment zone complex during the Trypanosoma brucei cell cycle. Fournal of Eukaryotic Microbiology 46, 105-109.

Lacomble, S., Vaughan, S., Gadelha, C., Morphew, M. K., Shaw, M. K., McIntosh, J. R. and Gull, K. (2009). Three-dimensional cellular architecture of the flagellar pocket and associated cytoskeleton in trypanosomes revealed by electron microscope tomography. Fournal of Cell Science 122, 1081-1090.

Lacomble, S., Vaughan, S., Gadelha, C., Morphew, M. K., Shaw, M. K., McIntosh, J. R. and Gull, K. (2010). Basal body movements orchestrate membrane organelle division and cell morphogenesis in Trypanosoma brucei. Fournal of Cell Science 123, 2884-2891.

LaCount, D. J., Bruse, S., Hill, K. L. and Donelson, J. E. (2000). Double-stranded RNA interference in Trypanosoma brucei using head-tohead promoters. Molecular and Biochemical Parasitology 111, 67-76.

Li, Z. (2012). Regulation of the cell division cycle in Trypanosoma brucei Eukaryotic Cell 11, 1180-1190.

Lozano-Núñez, A., Ikeda, K. N., Sauer, T. and de Graffenried, C. L. (2013). An analogue-sensitive approach identifies basal body rotation and flagellum attachment zone elongation as key functions of PLK in Trypanosoma brucei. Molecular Biology of the Cell 24, 1321-1333.

McAllaster, M. R., Ikeda, K. N., Lozano-Núñez, A., Anrather, D., Unterwurzacher, V., Gossenreiter, T., Perry, J. A., Crickley, R., Mercadante, C. J., Vaughan, S. and de Graffenried, C. L. (2015) Proteomic identification of novel cytoskeletal proteins associated with TbPLK, an essential regulator of cell morphogenesis in Trypanosoma brucei. Molecular Biology of the Cell 26, 3013-3029.

Mony, B. M., MacGregor, P., Ivens, A., Rojas, F., Cowton, A., Young, J., Horn, D. and Matthews, K. (2014). Genome-wide dissection of the quorum sensing signalling pathway in Trypanosoma brucei. Nature 505, 681-685.

Moreira-Leite, F. F., Sherwin, T., Kohl, L. and Gull, K. (2001). A trypanosome structure involved in transmitting cytoplasmic information during cell division. Science 294, 610-612.

Morgan, G. A., Laufman, H. B., Otieno-Omondi, F. P. and Black, S. J. (1993). Control of G1 to S cell cycle progression of Trypanosoma brucei S427cl1 organisms under axenic conditions. Molecular and Biochemical Parasitology 57, 241-252.

Morgan, G. W., Allen, C. L., Jeffries, T. R., Hollinshead, M. and Field, M. C. (2001). Developmental and morphological regulation of clathrin-mediated endocytosis in Trypanosoma brucei. Fournal of Cell Science 114, 2605-2615

Mutomba, M. C. and Wang, C.C. (1996). Effects of aphidicolin and hydroxyurea on the cell cycle and differentiation of Trypanosoma brucei bloodstream forms. Molecular and Biochemical Parasitology 80, 89-102. Ogbadoyi, E. O., Robinson, D. R. and Gull, K. (2003). A high-order trans-membrane structural linkage is responsible for mitochondrial genome positioning and segregation by flagellar basal bodies in trypanosomes. Molecular Biology of the Cell 14, 1769-1779.
Opperdoes, F. R. and Borst, P. (1977). Localization of nine glycolytic enzymes in a microbody-like organelle in Trypanosoma brucei: the glycosome. FEBS Letters 80, 360-364.

Perdomo, D., Bonhivers, M., Robinson, D. R. (2015). The trypanosome flagellar pocket collar and its ring forming protein-TbBILBO1. Cells 5. pii: E9. Robinson, D. R. and Gull, K. (1994). The configuration of DNA replication sites within the Trypanosoma brucei kinetoplast. Fournal of Cell Biology 126, 641-648.

Robinson, D. R., Sherwin, T., Ploubidou, A., Byard, E. H. and Gull, K. (1995). Microtubule polarity and dynamics in the control of organelle positioning, segregation, and cytokinesis in the trypanosome cell cycle. Fournal of Cell Biology 128, 1163-1172.

Rotureau, B. and Van Den Abbeele, J. (2013). Through the dark continent: African trypanosome development in the tsetse fly. Frontiers in Cellular and Infection Microbiology 3, 53.

Sevova, E. S. and Bangs, J. D. (2009). Streamlined architecture and glycosylphosphatidylinositol dependent trafficking in the early secretory pathway of African trypanosomes. Molecular Biology of the Cell 20, 4739-4750.

Sharma, R., Gluenz, E., Peacock, L., Gibson, W., Gull, K. and Carrington, M. (2009). The heart of darkness: growth and form of Trypanosoma brucei in the tsetse fly. Trends in Parasitology 25, 517-524.

Shaw, A. P., Cecchi, G., Wint, G. R., Mattioli, R. C. and Robinson, T. P. (2014). Mapping the economic benefits to livestock keepers from intervening against bovine trypanosomosis in Eastern Africa. Preventative Veterinary Medicine 113, 197-210.

Sheader, K., Vaughan, S., Minchin, J., Hughes, K., Gull, K. and Rudenko, G. (2005). Variant surface glycoprotein RNA interference triggers a precytokinesis cell cycle arrest in African trypanosomes. Proceedings of the National Academy of Sciences of the United States of America 102, $8716-8721$.

Shedden, K. and Cooper, S. (2002). Analysis of cell-cycle-specific gene expression in human cells as determined by microarrays and double-thymidine block synchronization. Proceedings of the National Academy of Sciences of the United States of America 99, 4379-4384.

Sherwin, T. and Gull, K. (1989). The cell division cycle of Trypanosoma brucei brucei: timing of event markers and cytoskeletal modulations. Philosophical Transactions of the Royal Society of London Series B: Biological Sciences 323, 573-588.

Shi, H., Djikeng, A., Mark, T., Wirtz, E., Tschudi, C. and Ullu, E. (2000). Genetic interference in Trypanosoma brucei by heritable and inducible double-stranded RNA. RNA 6, 1069-1076.

Siegel, T. N., Kawahara, T., Degrasse, J. A., Janzen, C. J., Horn, D. and Cross, G. A. (2008a). Acetylation of histone H4K4 is cell cycle regulated and mediated by HAT3 in Trypanosoma brucei. Molecular Microbiology 67, 762-771.

Siegel, T. N., Hekstra, D. R. and Cross, G. A. (2008b). Analysis of the Trypanosoma brucei cell cycle by quantitative DAPI imaging. Molecular and Biochemical Parasitology 160, 171-174.

Simarro, P.P., Cecchi, G., Franco, J. R., Paone, M., Diarra, A., Priotto, G., Mattioli, R. C. and Jannin, J. G. (2015). Monitoring the Progress towards the Elimination of Gambiense Human African Trypanosomiasis. PLoS Neglected Tropical Diseases 2015 9, e0003785.

Sudarshi, D., Lawrence, S., Pickrell, W. O., Eligar, V., Walters, R., Quaderi, S., Walker, A., Capewell, P., Clucas, C., Vincent, A., Checchi, F., MacLeod, A. and Brown, M. (2014). Human African trypanosomiasis presenting at least 29 years after infection--what can this teach us about the pathogenesis and control of this neglected tropical disease? PLoS Neglected Tropical Diseases 8, e3349.

Sunter, J. D. and Gull, K. (2016). The flagellum attachment zone: 'the cellular ruler' of trypanosome morphology. Trends in Parasitology 32 309-324.

Sunter, J. D., Varga, V., Dean, S. and Gull, K. (2015). A dynamic coordination of flagellum and cytoplasmic cytoskeleton assembly specifies cell morphogenesis in trypanosomes. Fournal of Cell Science 128, 1580-1594. Trindade, S., Rijo-Ferreira, F., Carvalho, T., Pinto-Neves, D., Guegan, F., Aresta-Branco, F., Bento, F., Young, S. A., Pinto, A., Van Den Abbeele, J., Ribeiro, R.M., Dias, S., Smith, T.K. and Figueiredo, L. M. (2016). Trypanosoma brucei parasites occupy and functionally adapt to the adipose tissue in mice. Cell Host and Microbe 19, 837-848. TrypTag. (2016). Tryp Tag.org - About TrypTag. [online]. http://tryptag. org

Vaughan, S., Kohl, L., Ngai, I., Wheeler, R. J. and Gull, K. (2008). A repetitive protein essential for the flagellum attachment zone filament structure and function in Trypanosoma brucei. Protist 159, 127-136.

Vaux, D. L. (2014). Basic statistics in cell biology. Annual Review of Cell and Developmental Biology 30, 23-37.

Vercesi, A. E., Moreno, S. N. and Docampo, R. (1994). Ca2+/H+ exchange in acidic vacuoles of Trypanosoma brucei. Biochemical Fournal 304, 227-233. 
Vickerman, K. (1985). Developmental cycles and biology of pathogenic trypanosomes. British Medical Bulletin 41, 105-114.

Wang, Z., Morris, J. C., Drew, M. E., Englund, P. T. (2000). Inhibition of Trypanosoma brucei gene expression by RNA interference using an integratable vector with opposing T7 promoters. Fournal of Biological Chemistry 275, 40174-9.

Weissgerber, T. L., Garovic, V. D., Milin-Lazovic, J. S., Winham, S J., Obradovic, Z., Trzeciakowski, J.P. and Milic, N. M. (2016). Reinventing Biostatistics Education for Basic Scientists. PLoS Biology 14, e1002430. Erratum in: PLoS Biology 2016 14(6):e1002492.

Welburn, S. C., Molyneux, D. H. and Maudlin, I. (2016). Beyond tsetse--implications for research and control of human African trypanosomiasis epidemics. Trends in Parasitology 32, 230-241.

Wheeler, R. J. (2015). Analyzing the dynamics of cell cycle processes from fixed samples through ergodic principles. Molecular Biology of the Cell 26, 3898-3903.

Wheeler, R. J., Gluenz, E. and Gull, K. (2011). The cell cycle of Leishmania: morphogenetic events and their implications for parasite biology. Molecular Microbiology 79, 647-662.

Wheeler, R. J., Gull, K. and Gluenz, E. (2012). Detailed interrogation of trypanosome cell biology via differential organelle staining and automated image analysis. BMC Biology 10, 1.
Wheeler, R. J., Gluenz, E. and Gull, K. (2013a). The limits on trypanosomatid morphological diversity. PLoS ONE 8, e79581.

Wheeler, R. J., Scheumann, N., Wickstead, B., Gull, K. and Vaughan, S. (2013b). Cytokinesis in Trypanosoma brucei differs between bloodstream and tsetse trypomastigote forms: implications for microtubule-based morphogenesis and mutant analysis. Molecular Microbiology 90, 1339-1355.

Wirtz, E., Leal, S., Ochatt, C. and Cross, G. A. (1999). A tightly regulated inducible expression system for conditional gene knock-outs and dominant-negative genetics in Trypanosoma brucei. Molecular and Biochemical Parasitology 99, 89-101.

Woodward, R. and Gull, K. (1990). Timing of nuclear and kinetoplast DNA replication and early morphological events in the cell cycle of Trypanosoma brucei. Fournal of Cell Science 95, 49-57.

World Health Organisation. (2016). Neglected tropical diseases Summary. [online]. http://www.who.int/neglected_diseases/diseases/en/ Zhang, X., Cui, J., Nilsson, D., Gunasekera, K., Chanfon, A., Song, X., Wang, H., Xu, Y. and Ochsenreiter, T. (2010). The Trypanosoma brucei MitoCarta and its regulation and splicing pattern during development. Nucleic Acids Research 38, 7378-7387.

Zhou, Q., Hu, H., He, C. Y. and Li, Z. (2015). Assembly and maintenance of the flagellum attachment zone filament in Trypanosoma brucei. Fournal of Cell Science 128, 2361-2372. 